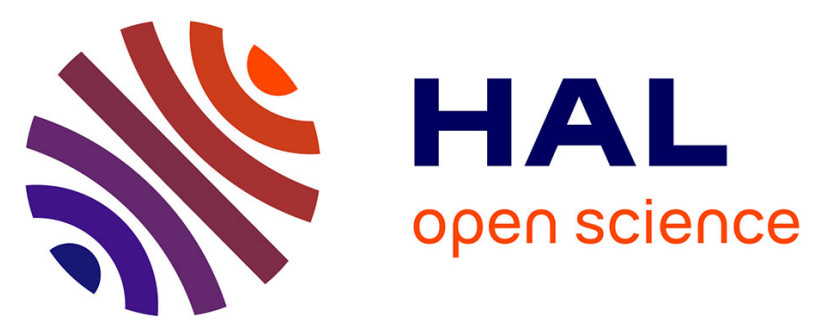

\title{
Isolation and characterisation of a bacterial strain degrading the herbicide sulcotrione from an agricultural soil
}

Christophe Calvayrac, Fabrice Martin-Laurent, Alexia Faveaux, Nathalie Picault, Olivier Panaud, Camille-Michel Coste, Hanene Chaabane, Jean-François Cooper

\section{To cite this version:}

Christophe Calvayrac, Fabrice Martin-Laurent, Alexia Faveaux, Nathalie Picault, Olivier Panaud, et al.. Isolation and characterisation of a bacterial strain degrading the herbicide sulcotrione from an agricultural soil . Pest Management Science, 2012, 68 (3), pp.340-347. 10.1002/ps.2263 . hal01137037

\section{HAL Id: hal-01137037 \\ https://hal.science/hal-01137037}

Submitted on 30 Mar 2015

HAL is a multi-disciplinary open access archive for the deposit and dissemination of scientific research documents, whether they are published or not. The documents may come from teaching and research institutions in France or abroad, or from public or private research centers.
L'archive ouverte pluridisciplinaire HAL, est destinée au dépôt et à la diffusion de documents scientifiques de niveau recherche, publiés ou non, émanant des établissements d'enseignement et de recherche français ou étrangers, des laboratoires publics ou privés. 


\title{
Isolation and characterisation of a bacterial strain degrading the herbicide sulcotrione from an agricultural soil
}

\author{
Christophe Calvayrac, ${ }^{\text {a,b }}$ Fabrice Martin-Laurent, ${ }^{c}$ Alexia Faveaux, $^{\text {a }}$ \\ Nathalie Picault, ${ }^{\text {b }}$ Olivier Panaud, ${ }^{\text {b }}$ Camille-Michel Coste, ${ }^{\text {a }}$ \\ Hanene Chaabane ${ }^{d}$ and Jean-François Cooper ${ }^{a *}$
}

\begin{abstract}
BACKGROUND: The dissipation kinetics of the herbicide sulcotrione sprayed 4 times on a French soil was studied using a laboratory microcosm approach. An advanced cultivation-based method was then used to isolate the bacteria responsible for biotransformation of sulcotrione. Chromatographic methods were employed as complementary tools to define its metabolic pathway.

RESULTS: Soil microflora was able quickly to biotransform the herbicide (DT $50 \approx 8$ days). 2-Chloro-4-mesylbenzoic acid, one of its main metabolites, was clearly detected. However, no accelerated biodegradation process was observed. Eight pure sulcotrione-resistant strains were isolated, but only one (10P) was capable of degrading this herbicide with a relatively high efficiency and to use it as a sole source of carbon and energy. In parallel, another sulcotrione-resistant strain (1TRANS) was shown to be incapable of degrading the herbicide. Amplified ribosomal restriction analysis (ARDRA) and repetitive extragenic palendromic PCR genomic (REP-PCR) fingerprinting of strains 1OP and 1TRANS gave indistinguishable profiles.
\end{abstract}

CONCLUSION: Sequencing and aligning analysis of 16S rDNA genes of each pure strain revealed identical sequences and a close phylogenetic relationship (99\% sequence identity) to Pseudomonas putida. Such physiological and genetic properties of $10 \mathrm{P}$ to metabolise sulcotrione were probably governed by mobile genetic elements in the genome of the bacteria.

(c) 2011 Society of Chemical Industry

Keywords: sulcotrione; biodegradation; soil; Pseudomonas putida; metabolites

\section{INTRODUCTION}

Sulcotrione [2-(2-chloro-4-methylsulfonylbenzoyl)-1,3-cyclohexanedione] is a triketone herbicide applied at $300-450 \mathrm{~g} \mathrm{ha}^{-1}$ on corn crop to control the development of a wide range of annual and perennial broadleaf weeds.

A large proportion of this herbicide reaches the soil, where both abiotic (i.e. sorption, chemical degradation) and biotic (biodegradation) processes control the fate and the activity of this herbicide. 2-Chloro-4-mesylbenzoic acid (CMBA) and 1,3-cyclohexanedione (CHD) have been described as biodegradation and hydrolysis transformation products. ${ }^{1-8}$ A derivative of phenylheptanoic acid was also described under special conditions. ${ }^{6,7,9}$ Hitherto, no report has shown the occurrence of accelerated biodegradation of sulcotrione as a result of repeated applications. Soil microorganisms able to transform sulcotrione are yet to be described, in contrast to mesotrione, another herbicide belonging to the triketone family. ${ }^{10-14}$ In this context, the aim of the present work was to evaluate the response of an agricultural soil regularly treated with sulcotrione, and possibly adapted to its biodegradation, in order to isolate novel and efficient sulcotrione degraders. Sulcotrione transformation was monitored in the soil using chromatographic methods. Sulcotrione-degrading bacterial strain was isolated by conducting an adaptation culture to the sulcotrione. The isolate was characterised by ARDRA, REP-PCR and by cloning/sequencing of the partial $16 \mathrm{~S}$ rDNA sequence. Its capacity to degrade aerobically sulcotrione was estimated.

Correspondence to: Jean-François Cooper, Laboratoire de Chimie des Biomolécules et de l'Environnement (LCBE, EA 4215), Université de Perpignan Via Domitia (UPVD), 52 avenue Paul Alduy, 66860 Perpignan, France. E-mail: cooper@univ-perp.fr

a Laboratoire de Chimie des Biomolécules et de l'Environnement, Université de Perpignan Via Domitia, Perpignan, France

b Laboratoire Génome et Développement des Plantes, Université de Perpignan Via Domitia, Perpignan, France

c INRA, Université de Bourgogne, UMR1229 Microbiologie du Sol et de I'Environnement, Dijon, France

d Unité de Recherche Protection Intégrée des Cultures, Institut National Agronomique de Tunisie, Tunis Mahrajène, Tunisia 


\section{MATERIALS AND METHODS}

\subsection{Experimental design}

\subsubsection{Experimental field site}

The experimental field site was set up at the University of Perpignan, France $\left(42^{\circ} 40^{\prime} 55^{\prime \prime} \mathrm{N}, 2^{\circ} 53^{\prime} 49^{\prime \prime} \mathrm{E}\right)$. The field was divided into two plots each of $184 \mathrm{~m}^{2}$, separated by a buffer strip. One plot (4S) was treated with $300 \mathrm{~g} \mathrm{ha}^{-1}$ of sulcotrione (Mikado ${ }^{\circledR}$ ) 4 times at 1 month intervals. After this, plot $4 \mathrm{~S}$ was neither pesticide treated nor cultivated for 24 months. The second plot (C), used as control, was never treated with sulcotrione. According to FAO classification, the soil is a clayey sandy loam soil. The soil physicochemical characteristics were: clay $13.9 \%$, silt $60.5 \%$, sand $25.6 \%$, soil moisture $25 \%$, organic carbon $0.9 \%$, organic nitrogen $0.98 \mathrm{~g} \mathrm{~kg}^{-1}, \mathrm{C} / \mathrm{N}$ ratio 9.64 , cation exchange capacity (CEC) 15.5 meq $100 \mathrm{~g}^{-1}, \mathrm{Ca}^{2+} / \mathrm{CEC} 214 \%$ and $\mathrm{pH}$ in water 8.1. Soil samples were collected from the surface layer $(0-7 \mathrm{~cm})$ of the experimental field. Composite samples were sieved to $2 \mathrm{~mm}$ and stored in the dark at $4{ }^{\circ} \mathrm{C}$ until use.

\subsubsection{Sulcotrione biodegradation}

The ability of the microflora of the soil samples collected on the experimental field ( $4 \mathrm{~S}$ and $\mathrm{C}$ ) to degrade sulcotrione was tested under laboratory conditions. Each microcosm, prepared with $10 \mathrm{~g}$ of moist soil placed in petri dishes $(5.5 \mathrm{~cm}$ ID), were treated with $550 \mu \mathrm{L}$ of sterile aqueous sulcotrione solution at $22 \mathrm{mg} \mathrm{L}^{-1}$ (i.e. $1.2 \mu \mathrm{g}$ of sulcotrione per $\mathrm{g}$ of soil) and homogenised. Treatments were applied 4 times at days $0,30,60$ and 90 (T1 $1_{\mathrm{D} 0}, \mathrm{~T} 2_{\mathrm{D} 30}, \mathrm{~T} 3_{\mathrm{D} 60}$ and $\left.\mathrm{T} 4_{\mathrm{D} 90}\right)$, necessitating the preparation of 40 microcosms for each soil type. All analyses were made in duplicate. In addition, autoclaved controls were set up to estimate the occurrence of abiotic biodegradation (St4S and $S t C$ ). All samples were kept in the dark to avoid photodegradation of the sulcotrione. Throughout the incubation period, soil moisture content was kept at 25\% (moist weight), making it comparable with field moisture. After each treatment, each entire soil aliquot $(10 \mathrm{~g})$ was regularly sampled (i.e. after $0,2,7,15$ and 30 days) to monitor sulcotrione dissipation.

\subsection{Chemical analysis}

\subsubsection{Reagents}

A standard of sulcotrione ( $98.8 \%$ purity) - a weak acidic herbicide, pKa value $2.87, \mathrm{MW} 328.77 \mathrm{~g} \mathrm{~mol}^{-1}$ and water solubility $165 \mathrm{mg} \mathrm{L}^{-1}$ at $25^{\circ} \mathrm{C}$ - was purchased from Sigma-Aldrich, France. Standards of 1,3-cyclohexanedione (CHD) (97.0\% purity) and 2chloro-4-mesylbenzoic acid (CMBA) (95.0\% purity) were purchased from Fluka and Acros Organics respectively.

Methanol and acetonitrile (HPLC quality) were purchased from Carlo Erba, dichloromethane for pesticide analysis from RiedeldeHaën $\mathrm{GmbH}$, trifluoroacetic acid (TFA) (99.0\% purity) from Aldrich and hydrochloric acid (38.0\%) from Prolabo, and water was Milli-Q quality. (Trimethylsilyl) diazomethane $2.0 \mathrm{M}$ in diethyl ether was supplied by Sigma-Aldrich. Supelclean ${ }^{\mathrm{TM}}$ ENVI-Chrom P SPE cartridges were supplied by Supelco, France.

\subsubsection{Analytical procedure}

\subsubsection{Degradation of sulcotrione in soil samples}

- Extraction step. Soil samples $(10 \mathrm{~g})$ were extracted twice with 60 and $30 \mathrm{~mL}$ of an acetonitrile/0.1 $\mathrm{M} \mathrm{HCl}(90 / 10 ; \mathrm{v} / \mathrm{v})$ mixture over 30 and 15 min periods, and then filtered on a Whatman filter GF/A. The organic filtrate was evaporated at $30^{\circ} \mathrm{C}$, and the acidic aqueous solution was then extracted twice with
$5.0 \mathrm{~mL}$ of dichloromethane. The organic phase was evaporated to dryness, and the extract was solubilised in $0.10 \mathrm{M} \mathrm{HCl}$. It was then purified on an EnviChrom $\mathrm{P}$ cartridge, eluted with methanol $(5 \mathrm{~mL})$ and concentrated to $1 \mathrm{~mL}$. The extract was finally analysed by HPLC. One blank (sulcotrione-free soil) was systematically included and analysed under the same conditions.

- Chromatographic analysis. Soil extracts were analysed using Shimadzu HPLC apparatus equipped with a Supelco ODS Hypersil $C_{18}$ column $(5 \mu \mathrm{m}, 250 \mathrm{~mm} \times 4.6)$ and an SPD-10 Avp UV/Vis detector set at $265 \mathrm{~nm}$. The mobile phase consisted of a mixture of water acidified by $0.3 \%$ trifluoroacetic acid (AW) and acetonitrile (ACN), delivered at a flow rate of $1 \mathrm{~mL} \mathrm{\textrm {min } ^ { - 1 }}$ and using a gradient system $[70 / 30$ (AW/ACN) at $t=0 \mathrm{~min}$ to $50 / 50$ (AW/ACN) at $8 \mathrm{~min}$, then maintained for $10 \mathrm{~min}$ ].

- Analytical performance. This analytical method was an adaptation of the procedure previously published by Chaabane et al. ${ }^{9}$ The quantification limit was estimated to be $0.05 \mu \mathrm{g} \mathrm{g}^{-1}$ for sulcotrione herbicide, with a mean recovery rate of $87 \pm 10 \%$.

\subsubsection{Degradation of sulcotrione by the bacterial culture}

- Extraction step. Aliquots $(1 \mathrm{~mL})$ of the bacterial culture (selected among sulcotrione-resistant ones) were centrifuged (15 min, $1100 \times g$ ) at room temperature. The supernatant was recovered, acidified with $0.3 \mathrm{~mL}$ of $0.16 \mathrm{M} \mathrm{HCl}$ and brought to $2.5 \mathrm{~mL}$ with distilled water. Then, the acidic aqueous solution was extracted twice with $2.5 \mathrm{~mL}$ of dichloromethane. The organic phase was evaporated to dryness and solubilised in $1 \mathrm{~mL}$ of methanol before analysis. No adsorption of sulcotrione was observed on the centrifuge tubes.

- High-performance liquid chromatography (HPLC/UV) of sulcotrione and its main metabolites. Culture medium extracts were analysed using Jasco HPLC apparatus equipped with a Supelco ODS Hypersil $C_{18}$ column $(5 \mu \mathrm{m}, 250 \mathrm{~mm} \times 4.6)$ and $a$ UV/visible detector Jasco 875-UV set at $265 \mathrm{~nm}$. The mobile phase consisted of a mixture of water acidified by $0.3 \%$ trifluoroacetic acid (AW) and acetonitrile (ACN), delivered at a flow rate of $1 \mathrm{~mL} \mathrm{~min}{ }^{-1}$. To improve the separation of the active ingredient and its metabolites during degradation kinetics, a gradient system [70/30 (AW/ACN) from 0 to $4 \mathrm{~min}$, evolving to $40 / 60$ (AW/ACN) at $7 \mathrm{~min}$, then maintained for $15 \mathrm{~min}$ ] was used. Detection of sulcotrione and its main metabolites (1,3-cyclohexanedione and 2-chloro-4-mesylbenzoic acid) was done at $265 \mathrm{~nm}$. Retention times were estimated as follows: sulcotrione $11.1 \mathrm{~min}$, CMBA $5.1 \mathrm{~min}$ and CHD $4.5 \mathrm{~min}$.

- High-performance liquid chromatography/mass spectrometry (HPLC/ESI/MS) analysis of metabolite 1,3-cyclohexanedione (CHD). LC/MS analysis was carried out on a LCQ-Fleet (Thermo Fisher Scientific) equipped with an electrospray ionisation (ESI) source and a 3D ion-trap analyser. LC analysis was achieved using an Accela Thermo Fisher chromatograph equipped with an Accela 600 pump, an Accela autosampler and a diode array detector (Accela PDA detector). Full-scan spectra from $\mathrm{m} / \mathrm{z} 60$ to 300 in both positive (source voltage $4 \mathrm{kV}$ ) and negative (source voltage $3.5 \mathrm{kV}$ ) ion modes were recorded. Separation was carried out at room temperature using a Phenomenex Gemini $\mathrm{C}_{6}$-phenyl column $(150 \times 3.0 \mathrm{~mm} ; 5 \mu \mathrm{m})$. The mobile phase consisted of a mixture of $0.1 \%$ formic acid water (A-W) and $0.1 \%$ formic acid acetonitrile (A-ACN) delivered at a flow rate of $0.4 \mathrm{~mL} \mathrm{~min}^{-1}$, with a gradient system: $90 / 10$ (A-W/A-ACN) from 0 to $2 \mathrm{~min}$, evolving to $10 / 90$ (A-W/A-ACN) at $20 \mathrm{~min}$. Under 


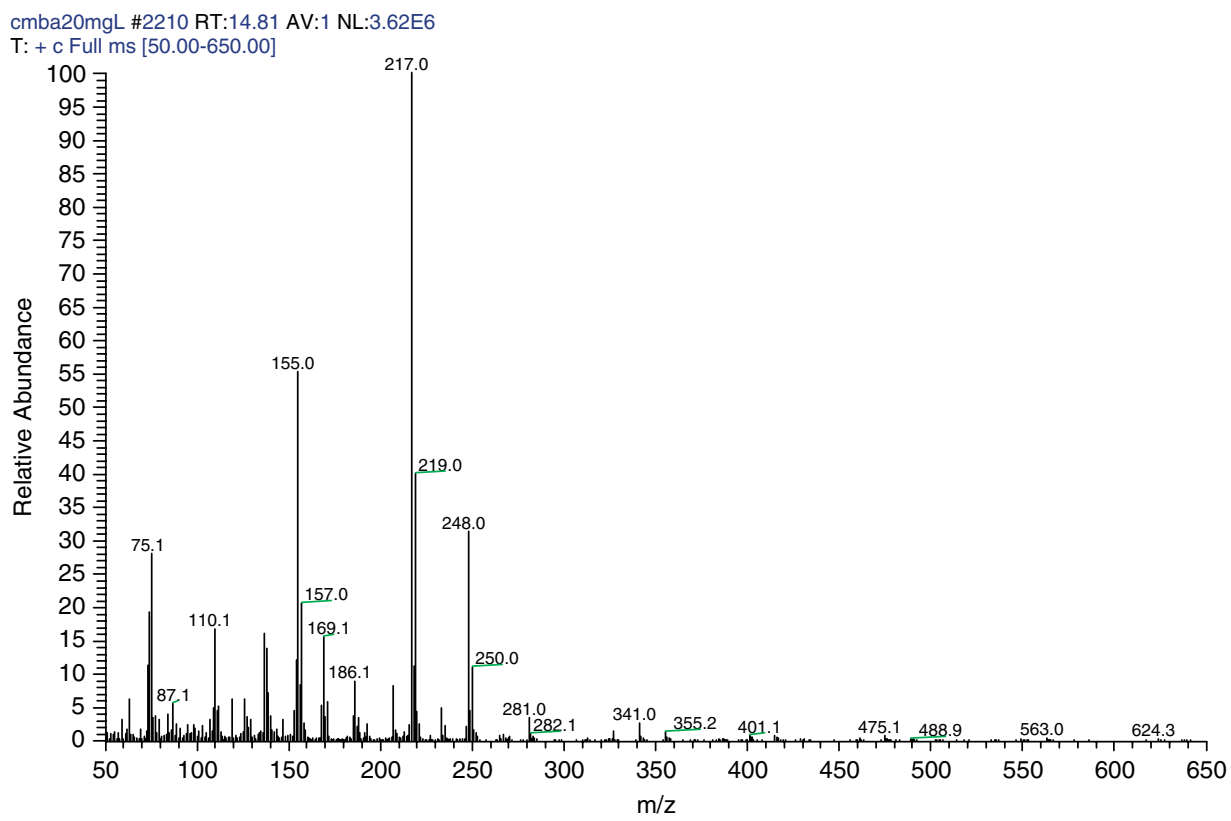

Figure 1. Electronic impact/mass spectrometry (EI/MS) spectrum of methylated CMBA analytical standard $\left(20 \mathrm{mg} \mathrm{L}^{-1}\right)$.

these conditions, the retention time of 1,3-CHD was $4.51 \mathrm{~min}$. The quantification limit was estimated in positive mode to be $0.5 \mathrm{mg} \mathrm{L}^{-1}$.

- Gas chromatography/mass spectrometry (GC/MS) analysis of metabolite 2-chloro-4-mesylbenzoic acid (CMBA) after derivatisation. In the presence of methanol, trimethylsilyldiazomethane (TMS) gives methyl esters in good yields at room temperature with various carboxylic acids including aromatic, heteroaromatic, alicyclic and aliphatic ones. The esterification proceeds instantaneously and quantitatively when an excess of TMS is used, and the reaction can be easily monitored by the disappearance of the yellow colour. ${ }^{15}$ TMS $(25 \mu \mathrm{L})$ prepared in diethyl ether solution was added to $0.5 \mathrm{~mL}$ of culture medium extract mixed with $0.5 \mathrm{~mL}$ of methanol. After a $2 \mathrm{~h}$ reaction time, the extract was analysed by GC/MS. GC/MS analysis was carried out on a Focus GC connected to a mass spectrometric detector DSQII (Thermo Fisher Scientific) equipped with a G-SQC GC column, $15 \mathrm{~m} \times 0.25 \mathrm{~mm} \times 0.25 \mu \mathrm{m}$ (5\% phenyl methylpolysiloxane), initial oven temperature $80^{\circ} \mathrm{C}$ for $1 \mathrm{~min}$, raised at $10^{\circ} \mathrm{C} \mathrm{min}{ }^{-1}$ to $260^{\circ} \mathrm{C}$ for $15 \mathrm{~min}$; carrier gas helium 6.0; electron impact mode $70 \mathrm{eV}$; full scan mode; split injection mode; transfer line temperature $300{ }^{\circ} \mathrm{C}$. Under such conditions, the retention time of methylated CMBA was $14.81 \mathrm{~min}$ and characteristic $m / z$ ions were 155, 217 and 248 (Fig. 1). A calibration curve was established on $\mathrm{m} / \mathrm{z} 217$ for the concentration range $0.4-20 \mathrm{mg} \mathrm{L}^{-1}\left(y=364 x-62, \mathrm{r}^{2}=0.996\right)$.

- Analytical performance. Culture medium samples were spiked with known amounts of analytical standards of sulcotrione, CHD and CMBA (2-30 $\left.\mathrm{mg} \mathrm{L}^{-1}\right)$. Calculations were made by HPLC/UV and/or GC/MS, after analysis in duplicate, using calibration curves. The mean recoveries were estimated as $75 \pm 6 \%, 55 \pm 8 \%$ and $75 \pm 10 \%$ for sulcotrione, $C H D$ and CMBA respectively. The limits of quantification, defined as the sample concentration required to give a signal-to-noise ratio of $5: 1$, were estimated to be $0.5-1.0 \mathrm{mg} \mathrm{L}^{-1}$.

\subsection{Isolation of the sulcotrione degrader}

\subsubsection{Culture media and cell preparation}

A culture medium (NS), where the nutrient source was the control soil C, was prepared and used to promote the growth of bacteria previously described as hardly cultivable on conventional culture media. ${ }^{16}$ Briefly, soil was sieved through a $2 \mathrm{~mm}$ mesh and dried at $65^{\circ} \mathrm{C}$ for 3 days. The culture medium was prepared by adding $40 \mathrm{~g}$ of soil and $2 \mathrm{~g}$ of agar in a final volume of $100 \mathrm{~mL}$ of deionised water. After sterilisation, the medium was supplemented with sterilised solutions of sulcotrione $\left(30 \mathrm{mg} \mathrm{L}^{-1}\right)$ and of cycloheximide (50 $\mathrm{mg} \mathrm{L}^{-1}$ ) and poured into petri dishes to solidify.

A sterile mineral salt medium (MS), modified from Rousseaux et al., ${ }^{17}$ was used for both the adaptation culture and the biodegradation assays of sulcotrione-degrading strains. This medium contained per litre: $1.6 \mathrm{~g}$ of $\mathrm{K}_{2} \mathrm{HPO}_{4}, 0.4 \mathrm{~g}$ of $\mathrm{KH}_{2} \mathrm{PO}_{4}, 0.2 \mathrm{~g}$ of $\mathrm{MgSO}_{4} .7 \mathrm{H}_{2} \mathrm{O}, 0.1 \mathrm{~g}$ of $\mathrm{NaCl}, 0.002 \mathrm{~g}$ of $\mathrm{CaCl}_{2}, 3.5 \mathrm{~g}$ of $\left(\mathrm{NH}_{4}\right)_{2} \mathrm{SO}_{4}$, $30 \mathrm{mg}$ of sulcotrione, $1 \mathrm{~mL}$ of salt stock solution, $1 \mathrm{~mL}$ of vitamin stock solution and $1 \mathrm{~mL}$ of FeSO $\mathrm{H}_{4} \cdot 6 \mathrm{H}_{2} \mathrm{O}$ stock solution $\left(5 \mathrm{~g} \mathrm{~L}^{-1}\right)$. The salt stock solution contained $2 \mathrm{~g}$ of boric acid, $1.8 \mathrm{~g}$ of $\mathrm{MnSO}_{4} \cdot \mathrm{H}_{2} \mathrm{O}$, $0.2 \mathrm{~g}$ of $\mathrm{ZnSO}_{4}, 0.1 \mathrm{~g}$ of $\mathrm{CuSO}_{4}$ and $0.25 \mathrm{~g}$ of $\mathrm{Na}_{2} \mathrm{MoO}_{4}$ (per litre). The vitamin stock solution contained $100 \mathrm{mg} \mathrm{L}^{-1}$ of thiamine- $\mathrm{HCl}$ and $40 \mathrm{mg} \mathrm{L}^{-1}$ of biotin. After sterilisation, $0.2 \mu \mathrm{m}$ filter sterilised sulcotrione, $\mathrm{FeSO}_{4} .6 \mathrm{H}_{2} \mathrm{O}$, and vitamin stock solutions were added to the medium. The $\mathrm{pH}$ was adjusted to 7.7 with aqueous $0.1 \mathrm{M}$ $\mathrm{NaOH}$ solution. A solid sulcotrione-MS medium obtained by adding $15 \mathrm{~g} \mathrm{~L}^{-1}$ of agar (Biokar Diagnostics, France) was used to test the capacity of the strains to grow on such a solid medium.

Triptic soy broth medium (TS) obtained by adding $15 \mathrm{~g} \mathrm{~L}^{-1}$ of agar (Biokar Diagnostics, France) supplemented with sulcotrione (30 $\mathrm{mg} \mathrm{L}^{-1}$ ) was used to purify bacterial strains by successive stricking. A sulcotrione-(TS) medium (BioMérieux, France) was also used to improve microbial biomass culture during batch cultures for degradation assays. Microbial biomass was harvested by centrifugation $\left(15 \mathrm{~min}, 1600 \times g\right.$ at $4{ }^{\circ} \mathrm{C}$ ), and the pellet was washed twice with Knapp buffer $\left(1 \mathrm{~g}\right.$ of $\mathrm{KH}_{2} \mathrm{PO}_{4} ; 1 \mathrm{~g}$ of $\mathrm{K}_{2} \mathrm{HPO}_{4}$; $4 \mathrm{mg}$ of $\mathrm{FeCl}_{3} ; 40 \mathrm{mg}$ of $\mathrm{MgSO}_{4} .7 \mathrm{H}_{2}$, per litre of deionised water, $\mathrm{pH}$ 
6.6) as described earlier ${ }^{18}$ before being resuspended in sulcotrioneMS medium to obtain an absorbance of $\sim 0.3$ at $600 \mathrm{~nm}$.

\subsubsection{Adaptation cultures to the sulcotrione}

Soil $4 \mathrm{~S}$ ( $10 \mathrm{~g}$ ) was suspended in $90 \mathrm{~mL}$ of $0.9 \% \mathrm{NaCl}$ and placed on an orbital shaker at $200 \mathrm{rpm}$ for $30 \mathrm{~min}$. Duplicates were carried out. Soil suspension aliquots $(500 \mu \mathrm{L})$ were plated on NS-sulcotrione or NS medium. Plates were incubated in the dark at $28^{\circ} \mathrm{C}$ for 7 days. Growing colonies identified as sulcotrione-resistant strains and/or possible degraders were selected, grown in $100 \mathrm{~mL}$ of Triptic soy broth (TS) medium supplemented with sulcotrione for $24 \mathrm{~h}$ at $30{ }^{\circ} \mathrm{C}$ under agitation. They were then plated on TS agar with sulcotrione.

For each isolated bacterial strain, a selective adaptation step was then carried out by performing five successive cultures $\left(A_{1}\right.$ to $\mathrm{A}_{5}$ ) in $100 \mathrm{~mL}$ of sulcotrione-MS medium at $28^{\circ} \mathrm{C}$ under agitation at $150 \mathrm{rpm}$ for 20 days. Subsequent studies were performed using $\mathrm{A}_{5}$ adaptation solutions.

\subsubsection{Estimation of the sulcotrione-degrading capability of the bacterial isolates}

The $A_{5}$ bacterial culture $(1 \mathrm{~mL}$ ) was grown in TS supplemented with sulcotrione. After $15 \mathrm{~h}$ of culture, bacterial cells were harvested in the late exponential growth phase by centrifugation $(15 \mathrm{~min}$, $1100 \times g, 4^{\circ} \mathrm{C}$ ). The bacterial pellets were washed twice with Knapp buffer and was resuspended in sulcotrione-MS medium to obtain an absorbance of $\sim 0.3$ at $600 \mathrm{~nm}$. They were then incubated at $28^{\circ} \mathrm{C}$ in the dark on an orbital shaker (200 rpm). An aliquot $(1 \mathrm{~mL})$ of each bacterial suspension was then regularly sampled $(0,6,15$ and 27 days) and analysed to establish the kinetics of degradation of sulcotrione and the appearance of its main metabolites. These degradation tests were realised in triplicate. One control without bacterial inoculums was also included.

\subsubsection{ARDRA, REP-PCR and partial 16S rRNA cloning and sequencing}

The extraction of bacterial genomic DNA was done following the protocol previously described by Cheneby et al. ${ }^{19}$ and purified using the GENECLEAN ${ }^{\circledR}$ Turbo kit according to the manufacturer's instructions (MP Biomedicals, Europe). DNA quality was checked by $1 \%(\mathrm{w} / \mathrm{v})$ agarose gel in $1 \times$ TBE buffer and quantified by spectrophotometry (NanoDrop ${ }^{\circledR} 2000$; Thermo Fisher Scientific).

Partial 16S rRNA sequences were amplified by PCR in a $50 \mu \mathrm{L}$ volume reaction containing $1 \mu \mathrm{M}$ of the universal primers $27 \mathrm{f}$ (5'-AGA GTT TGA TCM TGG CTC AG-3') and 1492r (5'-TAC GGH TAC CTT GTT ACG ACT T-3'), $200 \mu \mathrm{M}$ of each dNTP (Promega, USA), $2.5 \mathrm{U}$ of GoTaq DNA polymerase (Promega, USA) and $25 \mathrm{ng}$ of DNA. ${ }^{20}$ PCR reactions were carried out in a PTC-200 gradient cycler (MJ Research) under the following conditions: $5 \mathrm{~min}$ at $94{ }^{\circ} \mathrm{C}, 35$ cycles of $1 \mathrm{~min}$ at $94^{\circ} \mathrm{C}, 1 \mathrm{~min}$ at $55^{\circ} \mathrm{C}$ and $2 \min$ at $72^{\circ} \mathrm{C}$, plus an additional 15 min cycle at $72^{\circ} \mathrm{C}$. PCR products were then separated by electrophoresis on a $1 \%$ agarose gel, purified using the GENECLEAN ${ }^{\circledR}$ Turbo kit and quantified by spectrophotometry.

ARDRA profiles were obtained by digesting $16 \mathrm{~S}$ rRNA PCR fragments $(7 \mu \mathrm{L})$ with the restriction endonucleases Alul and Haelll (New England Biolabs ${ }^{\circledR}$ ) overnight at $37^{\circ} \mathrm{C}$. The obtained restriction fragments for each isolate were separated on a $2 \%(\mathrm{v} / \mathrm{w})$ Metaphor agarose gel in $1 \times$ TBE buffer ( $80 \mathrm{~V}$ for $3.5 \mathrm{~h}$ ).

Repetitive extragenic palendromic PCR (REP-PCR) was carried out with REP1R-I and REP2-1 primers, targeting the conserved stem of each REP-like sequence in the genome. ${ }^{21}$ DNA amplification was carried out in a $25 \mu \mathrm{L}$ mixture using $50 \mathrm{ng}$ of extracted DNA as template in $5 \mu \mathrm{L}$ of $5 \times$ Giescher buffer [83 mM of $\left(\mathrm{NH}_{4}\right)_{2} \mathrm{SO}_{4}$; $335 \mathrm{~mm}$ of Tris $\mathrm{HCl}, \mathrm{pH} 8.8 ; 150 \mathrm{~mm}$ of $\beta$-mercaptoethanol; $33.5 \mu \mathrm{M}$ EDTA, pH 8.8], $6.5 \mathrm{mM}$ of $\mathrm{MgCl}_{2}, 0.16 \mathrm{mg} \mathrm{mL}^{-1}$ of bovine serum albumin (BSA) (New England Biolabs ${ }^{\circledR}$ ), $1.25 \mathrm{~mm}$ of each dNTP, $0.1 \mu \mathrm{L} \mathrm{mL}^{-1}$ of dimethyl sulfoxide, $2 \mu \mathrm{M}$ of each of the two primers (REP1R-I and REP2-1) and $1 \mathrm{U}$ of GoTaq DNA polymerase. Amplifications were carried out in a PTC-200 gradient cycler (MJ Research): 1 cycle at $95^{\circ} \mathrm{C}$ for $6 \mathrm{~min}, 30$ cycles at $94^{\circ} \mathrm{C}$ for $1 \mathrm{~min}$, $40^{\circ} \mathrm{C}$ for $1 \mathrm{~min}$ and $65^{\circ} \mathrm{C}$ for $4 \mathrm{~min}$, plus an extension cycle at $65^{\circ} \mathrm{C}$ for 16 min. ${ }^{17}$ Amplified DNA fragments were separated by electrophoresis on $1 \%$ agarose gel. PCR reactions were performed independently in duplicate to ensure the consistency of the REP profiles obtained.

$16 \mathrm{~S}$ rRNA PCR products were cloned into the pGEM-T Easy vector according to the provider's recommendation (Promega, USA). Recombinant plasmids of interest were then purified by using Wizard ${ }^{\circledR}$ Plus Minipreps DNA Purification Systems kit (Promega). Both DNA strands of the insert were sequenced with an Applied Biosystems Hitachi 3130xl genetic analyser by using SP6 and T7 primers. Sequences of recombinant clones from the degrading and the non-degrading strains were treated by SeqManNGen ${ }^{\circledR}$ software (DNASTAR, USA) to provide consensus sequences, and were then compared with known sequences found in the GenBank database using Blast. ${ }^{22}$ Sequences were deposited in GenBank under the accession numbers JF303891 (1TRANS strain) and JF303892 (1OP strain). Multiple alignments were realised using the ClustalX programme. ${ }^{23}$ The phylogenetic tree was elaborated using the NJ plot programme. ${ }^{24}$

\section{RESULTS AND DISCUSSION}

\subsection{Sulcotrione degradation kinetics in Perpignan soils}

The microflora of the Perpignan soil was previously shown to transform sulcotrione to CHD and CMBA by cleaving the bond between 1,3-cyclohexanedione (CHD) and the benzoic ring. ${ }^{3}$ Here, the transformation of sulcotrione only in $4 \mathrm{~S}$ and $\mathrm{C}$ soils and not in the two sterilised soils ( $S t C$ and $S t 4 S$ ) is reported, further confirming the predominance of the biotic pathway for sulcotrione dissipation in the soil of Perpignan. Similar dissipation kinetics was observed in $\mathrm{C}$ and $4 \mathrm{~S}$ soils, which differed in herbicide treatment, the former never being treated with it and the latter having been treated 4 times at the agronomic dose 24 months ago. Indeed, after 30 days of incubation (treatment 1), almost $90 \%$ of the applied sulcotrione was dissipated, with half-lives averaging 8 days, without significant differences between $C$ and 45 plots. For both soils a no-lag-phase period was observed, which suggests that a cometabolic process is responsible for sulcotrione dissipation. By fitting sulcotrione dissipation kinetics with $R^{2}$ values close to 0.9 , it was possible to observe similar half-life values ( $\mathrm{DT}_{50} \approx 8$ days) and dissipation rates $\left(k \approx 0.08\right.$ day $^{-1}$ ) in $\mathrm{C}$ and $4 \mathrm{~S}$ soils (Table 1$)$. Compared with the literature, sulcotrione dissipation recorded in the soil of Perpignan is rather rapid when considering $\mathrm{DT}_{50}$ values. . $^{3,4,6-8,25}$ In addition, as plots $\mathrm{C}$ and $4 \mathrm{~S}$ showed a similar capacity to dissipate sulcotrione, besides different herbicide treatments, the possible accelerated biodegradation (ABD) of sulcotrione seems unlikely. To explore this possibility further, $C$ and $4 \mathrm{~S}$ soils were submitted to three additional sulcotrione treatments under laboratory conditions (T2 D30, T3 $3_{D 60}$ and T4 $\left.{ }_{D 90}\right)$. Similar dissipation kinetics of sulcotrione and kinetic parameters ( $k$ and $\mathrm{DT}_{50}$ ) were observed in these two plots which differed in scenario of exposure to sulcotrione (Table 1). In addition, no correlation could be found between the rate of degradation $(k)$ and the number of sulcotrione treatments. These results further 


\begin{tabular}{|c|c|c|c|c|}
\hline Plot & Treatment & $k\left(\right.$ days $\left.^{-1}\right)$ & $\mathrm{DT}_{50}$ (days) & $R^{2}$ \\
\hline \multirow[t]{5}{*}{ C plot } & Treatment $1\left(\mathrm{~T} 1_{\mathrm{D} 0}\right)$ & 0.083 & 8 & 0.894 \\
\hline & Treatment $2\left(\mathrm{~T} 2_{\mathrm{D} 30}\right)$ & 0.060 & 11.5 & 0.955 \\
\hline & Treatment $3\left(\mathrm{~T} 3_{\mathrm{D} 60}\right)$ & 0.100 & 7 & 0.989 \\
\hline & Treatment $4\left(T 4_{D 90}\right)$ & 0.100 & 7 & 0.962 \\
\hline & Mean value & $0.085 \pm 0.020$ & $8 \pm 2.5$ & - \\
\hline \multirow[t]{5}{*}{$4 \mathrm{~S}$ plot } & Treatment $1\left(\mathrm{~T} 1_{\mathrm{D} 0}\right)$ & 0.088 & 8 & 0.872 \\
\hline & Treatment $2\left(\mathrm{~T} 2_{\mathrm{D} 30}\right)$ & 0.093 & 7 & 0.936 \\
\hline & Treatment $3\left(\mathrm{~T} 3_{\mathrm{D} 60}\right)$ & 0.068 & 10 & 0.955 \\
\hline & Treatment $4\left(\mathrm{~T}_{\mathrm{D} 90}\right)$ & 0.089 & 8 & 0.828 \\
\hline & Mean value & $0.084 \pm 0.012$ & $8 \pm 2.0$ & - \\
\hline StC plot & Treatment $1\left(\mathrm{~T} 1_{\mathrm{D} 0}\right)$ & 0.0004 & - & - \\
\hline St4S plot & Treatment $1\left(\mathrm{~T} 1_{\mathrm{D} 0}\right)$ & 0.0004 & - & - \\
\hline
\end{tabular}

confirm that sulcotrione degradation most likely results from a cometabolic process, and that accelerated biodegradation did not occur in the soil of Perpignan. This feature was also observed for several other herbicides belonging to s-triazine or substituted urea families, for which degradation for a long period resulted from cometabolic activity of the soil microflora prior to the adaptation of the soil microflora to metabolic degradation relying on specific catabolic pathways. The switch between cometabolic and metabolic degradation of these two classes of herbicides occurred after almost 30 years of repeated exposure to these compounds of the agricultural fields. In order to gain a better insight into the processes involved in the dissipation of sulcotrione from the soil of Perpignan, an adaptation culture already shown to be successful in isolating different pesticide-degrading strains, including atrazine, isoproturon, carbofuran and mesotrione, was established. ${ }^{10,11,26-29}$

\subsection{Isolation of sulcotrione-degrading bacterial cultures}

The first step of the isolation process relied on the use of a soil agar medium NS supplemented with sulcotrione, adapted from Ferreira et al., ${ }^{16}$ and which was shown to promote the growth of pesticide-degrading bacterial strains known to be difficult to cultivate on conventional media, like most of the soil microbes. Starting from soil suspensions plated on NS-sulcotrione medium, numerous bacterial colonies showing different morphotypes grew. Eight colonies of the dominant morphotype, forming little white colonies, showing viscid consistency without mycelial growth, were further purified by successive plating. Except for their opaque or translucent appearance, these isolates showed comparable morphology, forming white colonies with a diameter of $\sim 2.5 \mathrm{~mm}$ and the following characteristics: smooth, circular form, convex elevation. Each of the eight colonies was then cultivated repeatedly on MS-sulcotrione $\left(A_{1} \rightarrow A_{5}\right)$, where they were able to grow. Nevertheless, as agar can also represent a source of carbon, the aptitude of these bacterial isolates to degrade sulcotrione was checked in MS-sulcotrione liquid medium.

\subsection{Estimation of the sulcotrione-degrading capacity of bacterial isolates}

To get enough microbial biomass to set up a batch experiment to follow sulcotrione transformation, each of the eight cultures was grown for $15 \mathrm{~h}$ in TS-herbicide medium. They were then diluted to

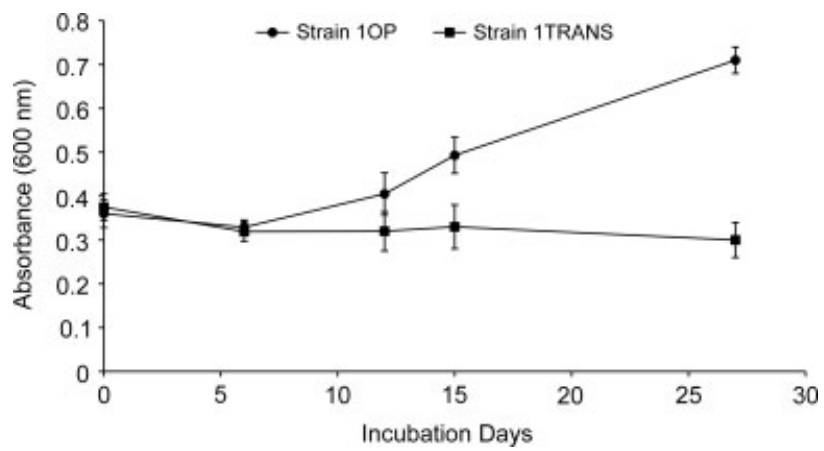

Figure 2. Growth measurement of strain 1OP versus 1TRANS on mineral salt medium (MS) supplemented with sulcotrione (100 $\mu \mathrm{M})$.

$0.3 \mathrm{OD}$ at $600 \mathrm{~nm}$ in MS herbicide-supplemented medium. Dissipation of herbicide and concomitant accumulation of CMBA and $\mathrm{CHD}$ in the culture medium were monitored by high-performance liquid chromatography. Among the eight isolates tested here, only $10 P$ showed an increased OD from 0.3 to $\sim 0.7$ after 30 days of incubation (Fig. 2), reflecting a bacterial growth using sulcotrione as carbon source. 1TRANS, one of the seven non-growing strains, was chosen as a non-degrading control. No significant growth was measured either for 1OP or for 1TRANS in MS sulcotrionefree medium under the same incubation conditions. It could be concluded that no interfering carbon sources are contained in MS medium, and that sulcotrione most likely constitutes the sole carbon and energy source for the growth of 1OP strain. HPLC/UV monitoring clearly showed the dissipation of sulcotrione in 1OP culture and not in the two controls - 1TRANS, the non-degrading isolate, and the uninoculated MS-sulcotrione medium (Fig. 3). Sulcotrione dissipation was clearly effective after 6 days lag phase, which was in accordance with the lag phase observed for the biomass development (Fig. 2). It could be hypothesised that this lag phase is the time necessary to induce the expression of the genes and the synthesis of the catabolic enzymes responsible for sulcotrione transformation. From the seventh day of incubation, sulcotrione dissipation kinetics could be reasonably described by a first-order kinetics $\left(C=121 \mathrm{e}^{-0.081 t}, R^{2}=0.993, n=3\right)$. $\mathrm{DT}_{50}$ could be estimated to be $\sim 15$ days after the beginning of the incubation.

During the time course of sulcotrione transformation, the appearance of 2-chloro-4-mesylbenzoic acid (CMBA), known as the main metabolite of sulcotrione herbicide (Fig. 3), could be observed. It has to be noted that this metabolite was observed in neither of the two controls-1TRANS, the non-degrading isolate, and the uninoculated MS-sulcotrione medium. CMBA was detected from the sixth day of incubation, which is in accordance with the lag phase observed for the initiation of sulcotrione disappearance. After 1 month of incubation, the concentration of CMBA reached $12 \pm 1 \mathrm{mg} \mathrm{L}^{-1}(48 \pm 3 \mu \mathrm{M})$ in the culture medium. This result was confirmed by $\mathrm{GC} / \mathrm{MS}$ analysis after derivatisation of CMBA to give the corresponding methyl ester. In addition, molar recovery, taking into account sulcotrione and $\mathrm{CMBA}$, was seen to decrease slightly between day 15 $\left(65 \pm 7 \mu \mathrm{mol} \mathrm{L}^{-1}+25 \pm 2 \mu \mathrm{mol} \mathrm{L}^{-1}\right.$ respectively) and day 27 $\left(17 \pm 2 \mu \mathrm{mol} \mathrm{L}^{-1}+48 \pm 3 \mu \mathrm{mol} \mathrm{L}^{-1}\right.$ respectively), suggesting a possible degradation of benzoic acid derivative CMBA by $10 \mathrm{P}$. Finally, based on the results presented here, it could be concluded that 1OP strain was capable of using sulcotrione as a carbon source for its growth by degrading sulcotrione to CMBA. 


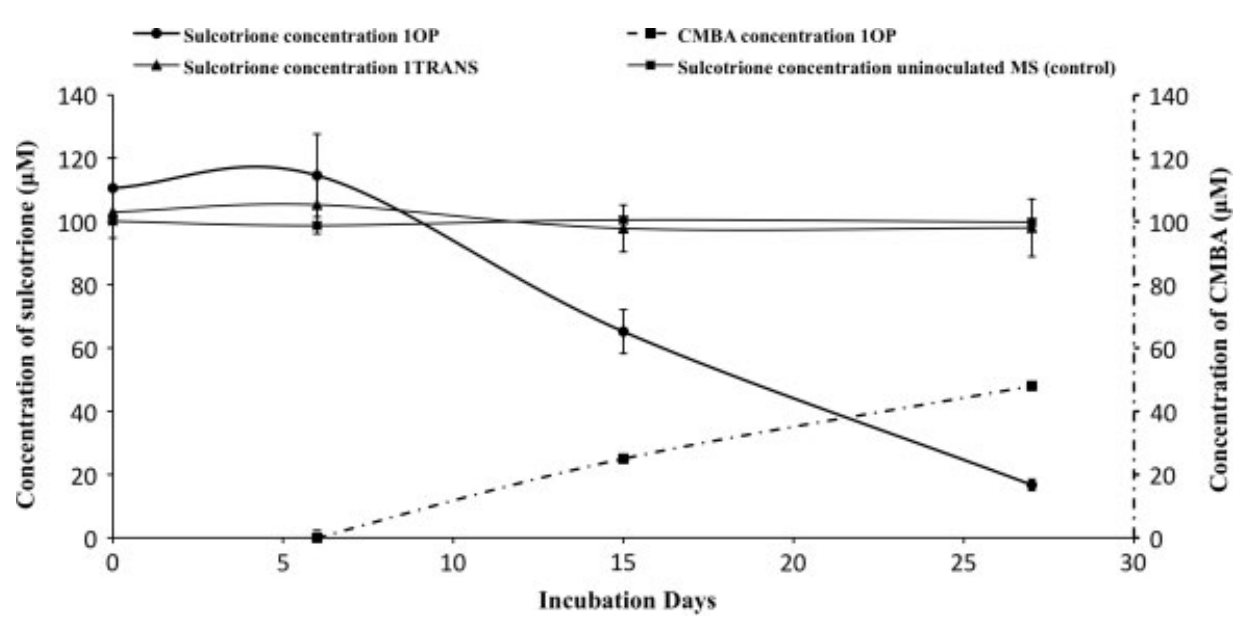

Figure 3. Dissipation of sulcotrione and accumulation of CMBA by strain 1OP versus control and strain 1TRANS in liquid mineral salt medium MS supplemented with sulcotrione $(100 \mu \mathrm{M})$. Errors bars indicate standard deviation.

1,3-Cyclohexanedione (CHD), the other degradation product of sulcotrione, previously identified at very low concentrations in the Perpignan soil, ${ }^{3}$ was not detected $\left(<0.2 \mathrm{mg} \mathrm{L}^{-1}\right)$ in the culture media of strain 1OP either by HPLC/UV or by HPLC/MS/MS. This discrepancy could be attributed to chemical transformation by hydrolysis of CHD to 5-oxohexanoic acid at $\mathrm{pH}>7$, or to an oxidation mechanism catalysed by enzymatic cleavage of $\mathrm{C}-\mathrm{C}$ bonds in the $\beta$-diketone before entering the tricarboxylic acid cycle (TCA), as previously reported. ${ }^{30-32}$ It is noteworthy that, for mesotrione, another herbicide belonging to the triketone family but with a nitro radical, a minor metabolic route catalysed by a Bacillus sp. with a comparable mechanism has been reported. ${ }^{11,12}$

\subsection{Characterisation of sulcotrione-degrading (1OP) and non-degrading (1TRANS) strains by ARDRA, REP-PCR and 165 rDNA sequencing}

The amplified ribosomal rDNA restriction analysis technique (ARDRA) has been reported to be a reliable and valuable tool for phylogenetic and taxonomic studies of large sets of cultured or uncultured microorganisms from different habitats. ${ }^{33-36}$ In this study, 1OP and 1TRANS isolate strains were characterised by ARDRA with Alul and Haell restriction endonucleases. 1OP and 1TRANS bacterial strains showed similar ARDRA profiles made up of four major bands of approximately 550, 380, 210 and 70 bp length. In order to obtain more taxonomical information than the genus level offered by ARDRA fingerprinting, 1OP and 1TRANS isolates were analysed by repetitive extragenic palindromic PCR (REP-PCR), which provides a rapid identification of bacterial isolates and is useful for the analysis of prokaryotic genomes. ${ }^{18,21}$ Again, 1OP and 1TRANS bacterial strains showed similar REP-PCR profiles made up of five major bands of approximately 550, 400, 270, 150 and 100 bp length (Fig. 4). This observation suggests that 1OP and 1TRANS belong to the same bacterial species. 16S rRNA sequencing further revealed that these two isolates showed identical 16S rRNA sequences. It is concluded that these isolates were different strains from the same species. Comparison of the $16 \mathrm{~S}$ rRNA sequence with those found in GenBank showed highest level of similarity (99\% similarity) to Pseudomonas sp. Furthermore, multiple alignments revealed that 1OP and 1TRANS 16S rRNA sequences were closely related to Pseudomonas putida strains both for 1OP and for 1TRANS (Fig. 5). Based on 16S rDNA phylogenetic data, it is suggested that the present sulcotrione-degrading isolate be named
Pseudomonas sp. 10P. It was classified as Bacteria, phylum Proteobacteria, class Gammaproteobacteria, order Pseudomonadales, family Pseudomonaceae and genus Pseudomonas, with the following characteristics: rod shaped, gram-negative, one or more flagella providing motility, positive catalase test and non-sporeforming bacteria. Several strains belonging to the Pseudomonas genus and able to degrade various pesticides have been described earlier, including Pseudomonas sp. ADP degrading atrazine, ${ }^{37}$ Pseudomonas cepacia DBO1 degrading 2,4-dichlorophenoxyacetic ${ }^{38}$ and Pseudomonas sp. degrading propoxur (2-isopropoxyphenyl$\mathrm{N}$-methylcarbamate). ${ }^{39}$ Interestingly, the isolation of two strains identical from the taxonomical point of view but differing in their sulcotrione-degrading capacity highlights the versatility of the degrading character. It could be hypothesised that such versatility might be due to mobile genetic elements (MGEs) surrounding catabolic genes in the genome of 1OP. MGEs such as plasmids, transposons, integrons, genomic islands and bacteriophages acted as a powerful evolutionary engine and regulator on microbial populations and were collectively referred to as drivers or vectors of 'the horizontal gene pool'. ${ }^{40,41}$ Such properties are known to be associated with various strains of genus Pseudomonas and its relatives, and were often specified by large $(>50 \mathrm{~kb}$ ) catabolic plasmids, although the catabolic genes could also be loaded on transposable elements. ${ }^{42-44}$ Further work will aim differentially to characterise the genetic determinants of the sulcotrione-degrading ability of Pseudomonas sp. 1OP.

\section{CONCLUSION}

This work confirms the aptitude of the soil microflora of Perpignan to transform sulcotrione, although no enhanced biodegradation was observed after repeated exposure to this herbicide. The isolation of a sulcotrione-degrading strain, identified as Pseudomonas putida strain 1OP, has been reported for the first time. This bacterial strain was shown to transform sulcotrione to 2-chloro4-mesylbenzoic acid (CMBA). Nevertheless, 1,3-cyclohexanedione (CHD), another known sulcotrione metabolite, was not detected. Based on the evolution of the molar recovery of sulcotrione and CMBA during the time course of dissipation kinetics, it has been hypothesised that Pseudomonas putida strain 10P may start degrading the benzoic acid derivative (CMBA) several days after its formation in the liquid medium. 


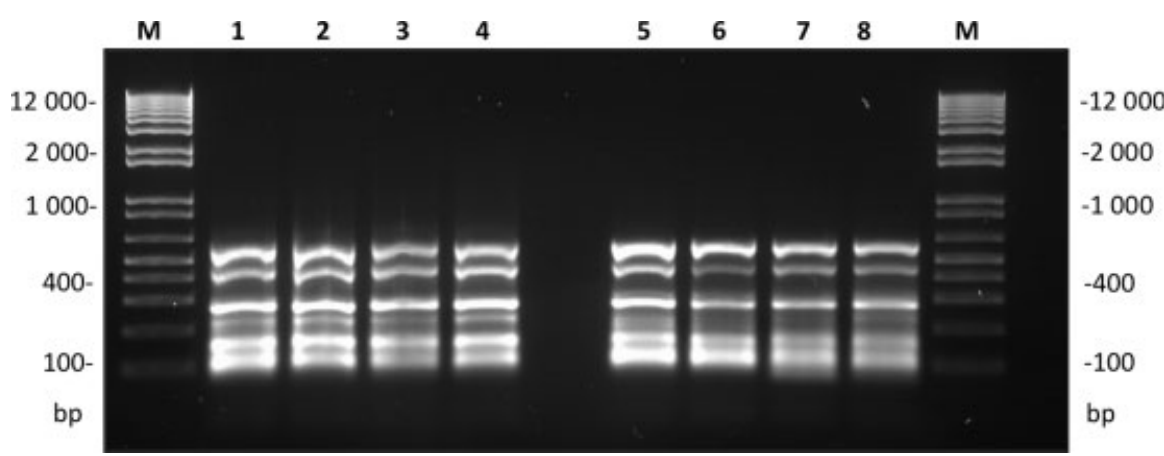

Figure 4. REP-PCR analysis of the isolates $1 \mathrm{OP}$ and 1TRANS. REP-PCR was performed in duplicate for each isolate with 1 or $2 \mathrm{ng} \mu \mathrm{L}^{-1}$ of DNA. Lane $\mathrm{M}$ represents the molecular weight marker $1 \mathrm{~Kb}$ Plus DNA Ladder (sizes indicated in base pairs). Lanes 1 and 2: 1TRANS (1 ng $\mu L^{-1}$ ); lanes 3 and 4: 1TRANS (2 $\left.\mathrm{ng} \mu \mathrm{L}^{-1}\right)$; lanes 5 and 6: $1 \mathrm{OP}\left(1 \mathrm{ng} \mu \mathrm{L}^{-1}\right)$; lanes 7 and 8: $1 \mathrm{OP}\left(2 \mathrm{ng} \mu \mathrm{L}^{-1}\right)$.

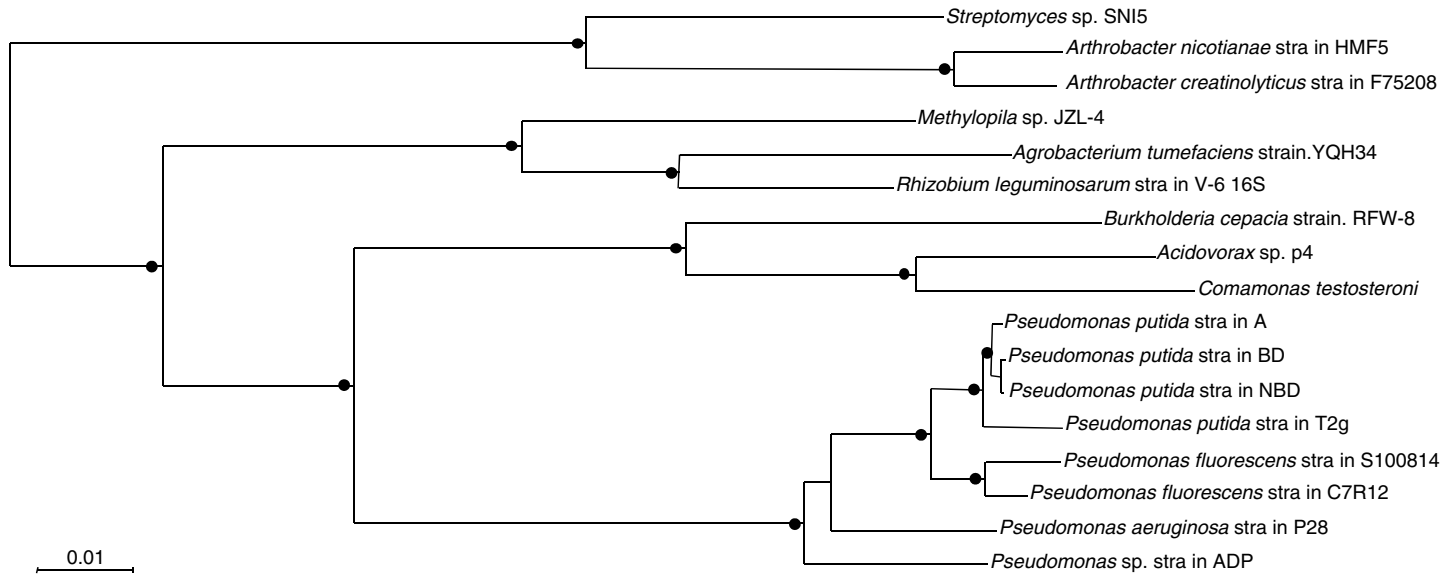

Figure 5. Neighbour-joining phylogenetic analysis resulting from the multiple alignment of 16S rRNA gene sequences of Pseudomonas putida strains 1TRANS (NBD) and 1OP (BD) with those retrieved from the GenBank database: Arthrobacter creatinolyticus strain F75208 (HQ908759), Arthrobacter nicotianae strain HMF5 (GU220490), Streptomyces sp. SNI5 (GU320191), Rhizobium leguminosarum strain V-6 (GU306144), Agrobacterium tumefaciens strain YQH34 (HQ143653), Methylopila sp. JZL-4 (FJ502233), Burkholderia cepacia strain RFW-8 (HQ650586), Comamonas testosteroni strain H18 (EU887829), Acidovorax sp. p4(HQ652596), Pseudomonas putida strain A (HQ697262), Pseudomonas putida strain T2g (AB539810), Pseudomonas aeruginosa strain P28 (HQ697285), Pseudomonas fluorescens strain C7R12 (AM229082), Pseudomonas fluorescens strain (HQ880245) and Pseudomonas sp. strain ADP (AM088478). Bootstrap values greater than $90 \%$ are marked as black circles. The phylogenetic distance is shown on the scale bar.

\section{ACKNOWLEDGEMENTS}

The PhD work of Christophe Calvayrac was funded by Bayer Cropscience. The authors also acknowledge the members of laboratories of UPVD (LCBE, LGDP, IMAGE and IUT), INSA Toulouse and INRA Dijon, France.

\section{REFERENCES}

1 Mamy L, Gabrielle B and Barriuso E, Comparative environmental impacts of glyphosate and conventional herbicides when used with glyphosate-tolerant and non-tolerant crops. Environ Pollut 158:3172-3178 (2010)

2 Chaabane $\mathrm{H}$, Vulliet $\mathrm{E}$, Joux F, Lantoine F, Conan P, Cooper JF, et al, Photodegradation of sulcotrione in various aquatic environments and toxicity of its photoproducts for some marine micro-organisms. Water Res 41:1781-1789 (2007).

3 Chaabane H, Vulliet E, Calvayrac C, Coste CMand Cooper JF, Behaviour of sulcotrione and mesotrione in two soils. Pest Manag Sci 64:86-93 (2008).

4 Cherrier R, Perrin-Ganier C and Schiavon M, Degradation of sulcotrione in a brown soil with various organic matters. Agronomie 24:29-33 (2004).

5 Maeghe L, Desmet EM and Bulcke R, Soil activity and persistence of sulcotrione and mesotrione. Commun Agric Appl Biol Sc 69:41-48 (2004).
6 Rouchaud J, Thirion A, Callens D and Bulcke R, Soil dissipation of the post-emergence herbicide sulcotrione in maize crops treated with organic fertilizers. Bull Environ Contam Toxicol 57:398-405 (1996).

7 Rouchaud J, Neus O, Bulcke R, Cools K and Eelen H, Sulcotrione soil metabolism in summer corn crops. Bull Environ Contam Toxicol 61:669-676 (1998).

8 Rouchaud J, Neus O, Callens D and Bulcke R, Sulcotrione soil persistence and mobility in summer maize and winter wheat crops. Weed Res 38:361-371 (1998).

9 Chaabane H, Cooper JF, Azouzi L and Coste CM, Influence of soil properties on the adsorption-desorption of sulcotrione and its hydrolysis metabolites on various soils. I Agric Food Chem 53:4091-4095 (2005).

10 Durand S, Amato P, Delort AM, Combourieu B and Besse-Hogan $\mathrm{P}$, First isolation and characterization of a bacterial strain that biotransforms the herbicide mesotrione. Lett Appl Microbiol 43:222-228 (2006).

11 Durand S, Legeret B, Martin A, Sancelme M, Delort A, BesseHoggan $P$, etal, Biotransformation of the triketone herbicide mesotrione by a Bacillus strain. Metabolite profiling using liquid chromatography/electrospray ionization quadrupole time-of-flight mass spectrometry. Rapid Commun Mass Spectrom 20:2603-2613 (2006).

12 Durand S, Sancelme M, Besse-Hoggan P and Combourieu B, Biodegradation pathway of mesotrione: complementarities of NMR, LC-NMR and LC-MS for qualitative and quantitative metabolic profiling. Chemosphere 81:372-380 (2010). 
13 Batisson I, Crouzet O, Besse-Hoggan P, Sancelme M, Mangot JF, Mallet $C$, et al, Isolation and characterization of mesotrionedegrading Bacillus sp. from soil. Environ Pollut 157:1195-1201 (2009).

14 Crouzet O, Batisson I, Besse-Hoggan P, Bonnemoy F, Bardot C, Poly F, et al, Response of soil microbial communities to the herbicide mesotrione: a dose-effect microcosm approach. Soil Biol Biochem 42:193-202 (2010).

15 Mashimoto N, Aoyama T and Shiori T, New methods and reagents in organic synthesis. A simple efficient preparation of methyl esters with trimethylsilyldiazomethane $\left(\mathrm{TMSCHN}_{2}\right)$ and its application to gas chromatographic analysis of fatty acids. Chem Pharm Bull 29:1475-1478 (1981).

16 Ferreira EPDB, Dusi AN, Costa JR, Xavier GR and Rumjanek NG, Assessing insecticide and fungicide effects on the culturable soil bacterial community by analyses of variance of their DGGE fingerprinting data. Eur J Soil Biol 45:466-472 (2009).

17 Rousseaux S, Hartmann A and Soulas G, Isolation and characterisation of a new Gram-negative and Gram-positive atrazine degrading bacteria from different French soils. FEMS Microbiol Ecol 36:211-222 (2001).

18 Devers M, Henry S, Hartmann A and Martin-Laurent F, Horizontal gene transfer of atrazine-degrading genes (atz) from Agrobacterium tumefaciens St96-4 Padp::Tn5 to bacteria of maize-cultivated soil. Pest Manag Sc 61:870-880 (2005).

19 Cheneby D, Perrez S, Devroe C, Hallet S, Couton Y, Bizouard F, et al, Denitrifying bacteria in bulk and maize-rhizospheric soil: diversity and $\mathrm{N}_{2} \mathrm{O}$-reducing abilities. Can J Microbiol 50:469-474 (2004).

20 Gurtler V and Stanisich VA, New approaches to typing and identification of bacteria using the 16S-23S rDNA spacer region. Microbiology 142:3-16 (1996).

21 Versalovic J, Koeuth TR and Lupski J, Distribution of repetitive DNA sequences in eubacteria and application to fingerprinting of bacterial genomes. Nucleic Acids Res 19:6823-6831 (1991).

22 GenBank $^{\circledR}$. [Online]. Available: http://blast.ncbi.nlm.nih.gov/Blast.cgi (2011).

23 Thompson JD, Gibson TJ, Plewniak F, Jeanmougin F and Higgins DG, The ClustalX windows interface: flexible strategies for multiple sequence alignment aided by quality analysis tools. Nucleic Acids Res 24:4876-4882 (1997).

24 Perriere G and Gouy M, WWW-Query: an on-line retrieval system for biological sequence banks. Biochimie 78:364-369 (1996).

25 Cherrier R, Boivin A, Perrin-Ganier C and Schiavon M, Sulcotrione versus atrazine transport and degradation in soil columns. Pest Manag Sci 61:899-904 (2005).

26 Govantes F, García-Gonzalez V, Porrua O, Platero Al, JimenezFernandez $A$ and Santero E, Regulation of the atrazine-degradative genes in Pseudomonas sp. strain ADP. FEMS Microbiol Lett 310:1-8 (2010).

27 El-Sebai T, Lagacherie B, Soulas G and Martin-Laurent F, Isolation and characterisation of an isoproturon-mineralising Methylopila sp. TES from French agricultural soil. FEMS Microbiol Lett 239:103-110 (2004).

28 Hussain S, Devers-Lamrani M, El Azhari N and Martin-Laurent F, Isolation and characterization of an isoproturon mineralizing Sphingomonas sp. strain SH from a French agricultural soil. Biodegradation 22:637-650 (2011).
29 Yano H, Garruto CE, Sota M, Ohtsubo Y, Nagata Y, Zylstra GJ, et al, Complete sequence determination combined with analysis of transposition/site-specific recombination events to explain genetic organization of IncP-7 TOL plasmid pWW53 and related mobile genetic elements. J Mol Biol 369:11-26 (2007).

30 Dangel W, Tschech A and Fuchs G, Enzyme reactions involved in anaerobic cyclohexanol metabolism by a denitrifying Pseudomonas species. Arch Microbiol 62:3245-3250 (1989).

31 Grogan G, [beta]-Diketone hydrolases. International Symposium on Biocatalysis and Biotransformations No. 5, Darmstadt, Germany. J Mol Catalysis. B, Enzymatic 19-20:73-82 (2002).

32 Grogan G, Emergent mechanistic diversity of enzyme-catalysed [beta]Diketone cleavage. Biochem J 388:721-730 (2005).

33 Vaneechoutte M, Rossau R, de Vos P, Gillis M, Janssens D, Paepe N, et al, Rapid identification of bacteria of the Comamonadaceae with amplified ribosomal DNA-restriction analysis (ARDRA). FEMS Microbiol Lett 72:227-233 (1992).

34 Vaneechoutte M, De Beenhouwer H, Claeys G, Verschraegen G, De Rouck A, Paepe N, et al, Identification of Mycobacterium species by using amplified ribosomal DNA-restriction analysis. J Clin Microbiol 31:2061-2065 (1993).

35 Martinez-Murcia AJ, Acinas SG and Rodriguez-Valera F, Evaluation of prokaryotic diversity by restrictase digestion of $16 \mathrm{~S}$ rDNA directly amplified from hypersaline environments. FEMS Microbiol Ecol 36:247-256 (1995)

36 Martin-Laurent F, Philippot L, Hallet S, Chaussod R, Germon JC, Soulas G, et al, DNA extraction from soils: old bias for new microbial diversity analysis method. Appl Environ Microbiol 67:2354-2359 (2001).

37 Mandelbaum R, Allan D and Wackett LP, Isolation and characterization of a Pseudomonas sp. that mineralizes the s-triazine herbicide atrazine. Appl Environ Microbiol 61:1451 - 1457 (1995).

38 Daugherty DD and Karel SF, Degradation of 2,4-dichlorophenoxyacetic acid by Pseudomonas cepacia DBO1(pRO101) in a dual-substrate chemostat. Appl Environ Microbiol 60:3261-3267 (1994).

39 Kamanavalli $\mathrm{CM}$ and Ninnekar $\mathrm{HZ}$, Biodegradation of propoxur by Pseudomonas species. World J Microbiol Biotechnol 16:329-331 (2000).

40 Thomas CM and Nielsen KM, Mechanisms and barriers to horizontal gene transfer between bacteria. Nat Rev Microbio/ 3:711-721 (2005).

41 Frost LS, Leplae R, Summers AO and Toussaint A, Mobile genetic elements: the agents of open source evolution. Nat Rev Microbiol 3:722-732 (2005).

42 Ogawa N, Chackrabarty AM and Zaborina O, Degradative plasmid, in Plasmid Biology, ed. by Funnell BE and Philipps GJ. ASM Press, Washington, DC, pp. 341-392 (2004)

43 Williams PA, Jones RM and Zylstra GJ, Genomics of catabolic plasmids, in Pseudomonas. Vol. 1, ed. by Ramos JL. Kluwer Academic/Plenum Publishers, New York, NY, pp. 165-195 (2004).

44 Yano H, Garruto CE, Sota M, Ohtsubo Y, Nagata Y, Zylstra GJ, et al, Complete sequence determination combined with analysis of transposition/site-specific recombination events to explain genetic organization of IncP-7 TOL plasmid pWW53 and related mobile genetic elements. J Mol Biol 369:11-26 (2007). 